\title{
Airway management of a patient with tracheal stenosis for surgery in the prone position
} [Contrôle des voies aériennes pour une intervention chirurgicale en décubitus ventral chez un patient avec sténose trachéale]

Takashi Asai MD PhD, Koh Shingu MD

Purpose: When tracheal intubation is required in a patient with an uncollapsible tracheal stenosis, the tip of the tube is usually positioned proximal to the stenosis. Only the tip of the tube may be in the trachea and the tube can be dislodged. We report the successful airway management of a patient with an uncollapsible tracheal stenosis who underwent cranial surgery in the prone position.

Clinical features: A 49-yr-old man with the saber-sheath trachea (stenosis of the entire intrathoracic trachea) was scheduled for a posterior fossa surgery for resection of a cerebellar tumour. Anesthesia was induced by allowing the patient to inhale spontaneously oxygen and increasing concentrations of sevoflurane up to $5 \%$, without airway obstruction. After injection of vecuronium, an airway exchange catheter was inserted orally into the trachea. A laryngeal mask airway was then inserted with the exchange catheter in place and, with the aid of a fibrescope, a 6.0-mm reinforced tracheal tube was passed through the laryngeal mask into the trachea so that the tip of the tube was about $1 \mathrm{~cm}$ proximal to the stenosis. The patient was turned to the prone position and the operation proceeded uneventfully.

Conclusions: The laryngeal mask and an airway exchange catheter were used as backups to tracheal intubation in this patient with tracheal stenosis in the prone position. Should the trachea be extubated accidentally, it may be re-intubated through the laryngeal mask and ventilation may be possible through the laryngeal mask or the exchange catheter.

\footnotetext{
Objectif : Si l'intubation endotrachéale est nécessaire chez un patient qui présente une sténose trachéale sans trachéomalacie, la pointe du tube est habituellement proximale à la sténose. La pointe seulement peut être logée dans la trachée et le tube peut être délogé. Nous présentons un cas de contrôle des voies aériennes réussi en présence de sténose trachéale sans trachéomalacie lors d'une intervention crânienne en décubitus ventral.
}

Éléments cliniques : Un homme de 49 ans présentait une trachée en fourreau de sabre (sténose de toute la trachée intrathoracique) et devait subir une opération de la fosse cérébrale postérieure pour la résection d'une tumeur cérébelleuse. L'anesthésie a été induite avec l'inhalation d'oxygène et des concentrations croissantes de sévoflurane, jusqu'à $5 \%$, sans obstruction des voies aériennes. Après l'injection de vécuronium, une sonde d'échange a été introduite dans la trachée par voie buccale. Un masque laryngé a été inséré ensuite, le cathéter toujours en place, et à l'aide d'un fibroscope, un tube trachéal armé de 6,0 mm a été glissé dans la trachée au travers du masque de sorte que la pointe du tube soit proximale à la sténose d'environ I centimètre. Le patient a été placé en décubitus ventral et l'opération s'est déroulée sans incident.

Conclusion : Le masque laryngé et une sonde d'échange ont été utilisés comme auxiliaires à l'intubation trachéale, chez un patient qui présentait une sténose trachéale, pour une opération en décubitus ventral. Si une extubation accidentelle survenait, il était possible de réintuber au travers du masque laryngé et d'assurer la ventilation par le masque laryngé ou la sonde d'échange.

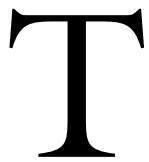

HE saber-sheath trachea is defined as a deformed intrathoracic trachea with an internal coronal diameter two-thirds of, or less than, its internal sagittal diameter. ${ }^{1}$ Although the mechanism for this deformity is unclear, it has been speculated that recurrent coughing repeatedly injures the trachea and the trachea becomes deformed after regeneration of damaged cartilages. ${ }^{1,2}$ The deformed trachea is usually densely ossified and is unlikely to collapse.

The airway management of the patient with a tracheal stenosis is a challenge to anesthesiologists. Airway management can become more difficult when

From the Department of Anesthesiology, Kansai Medical University, Osaka, Japan.

Address correspondence to: Dr. Takashi Asai, Department of Anesthesiology, Kansai Medical University, 10-15 Fumizono-cho,

Moriguchi City, Osaka, 570-8507, Japan. Phone: 0081-6-6992-1001; Fax: 0081-6-6991-1301; E-mail: asait@takii.kmu.ac.jp Accepted for publication August 26, 2003.

Revision accepted April 2, 2004. 
such a patient requires surgery in the prone position. There have been no reports of airway management of a patient with tracheal stenosis undergoing surgery in the prone position. We report successful management of the airway in such a patient.

\section{Case presentation}

A 49-yr-old man, height $165 \mathrm{~cm}$, weight $65 \mathrm{~kg}$, was scheduled for posterior fossa surgery for resection of a cerebellar tumour. Preoperative chest $x$-ray revealed a tracheal stenosis, starting at the level of the sternal notch and extending to the carina. The extrathoracic trachea, between the level of the glottis and the sternal notch, was normal. Computed tomography also showed a normal extrathoracic trachea but a deformed intrathoracic trachea, in which the coronal diameter was less than one half that of the sagittal diameter. The narrowest calibre was about $5 \mathrm{~mm}$. The diagnosis of saber-sheath trachea was made.

Pulmonary function studies indicated obstructive airway disease with a ratio of FEVI to forced vital capacity of $53 \%$; vital capacity was $87 \%$ of predicted. Analysis of arterial blood gases showed $\mathrm{PaO}_{2} 80$ $\mathrm{mmHg}, \mathrm{PaCO}_{2} 44 \mathrm{mmHg}$, and $\mathrm{pH}$ 7.4. Despite the tracheal stenosis, the patient had no respiratory symptoms. Clear breath sounds were heard equally over both lung fields. No chest wall retraction was observed.

In the operating room, an electrocardiograph, pulse oximeter and blood pressure cuff were attached. After pre-oxygenation of the patient, anesthesia was induced by allowing the patient to inhale spontaneously oxygen and increasing concentrations of sevoflurane up to $5 \%$, without airway obstruction. A laryngoscope was inserted to confirm that the glottis could be seen. Vecuronium $8 \mathrm{mg}$ was injected intravenously, and the lungs were ventilated manually via a facemask without difficulty.

After neuromuscular blockade was established, a laryngoscope was inserted and an airway exchange catheter (Cook, Bloomington, IN, USA; internal diameter: $1.6 \mathrm{~mm}$; outer diameter: $2.7 \mathrm{~mm}$, length 45 $\mathrm{cm})$ was inserted orally into the trachea until the 23 $\mathrm{cm}$ mark had just passed the gap between the right upper and lower molars; the catheter was fixed to the right cheek. A size 5 laryngeal mask airway was then inserted without difficulty (with the exchange catheter in place) and provided adequate ventilation. The correct position of the laryngeal mask was confirmed by passing a fibreoptic bronchoscope down the laryngeal mask. With the aid of the fibrescope, a reinforced tracheal tube (internal diameter: $6.0 \mathrm{~mm}$; Mallinckrodt, Athlone, Ireland) was passed through the laryngeal mask into the trachea so that the tip of the tube was

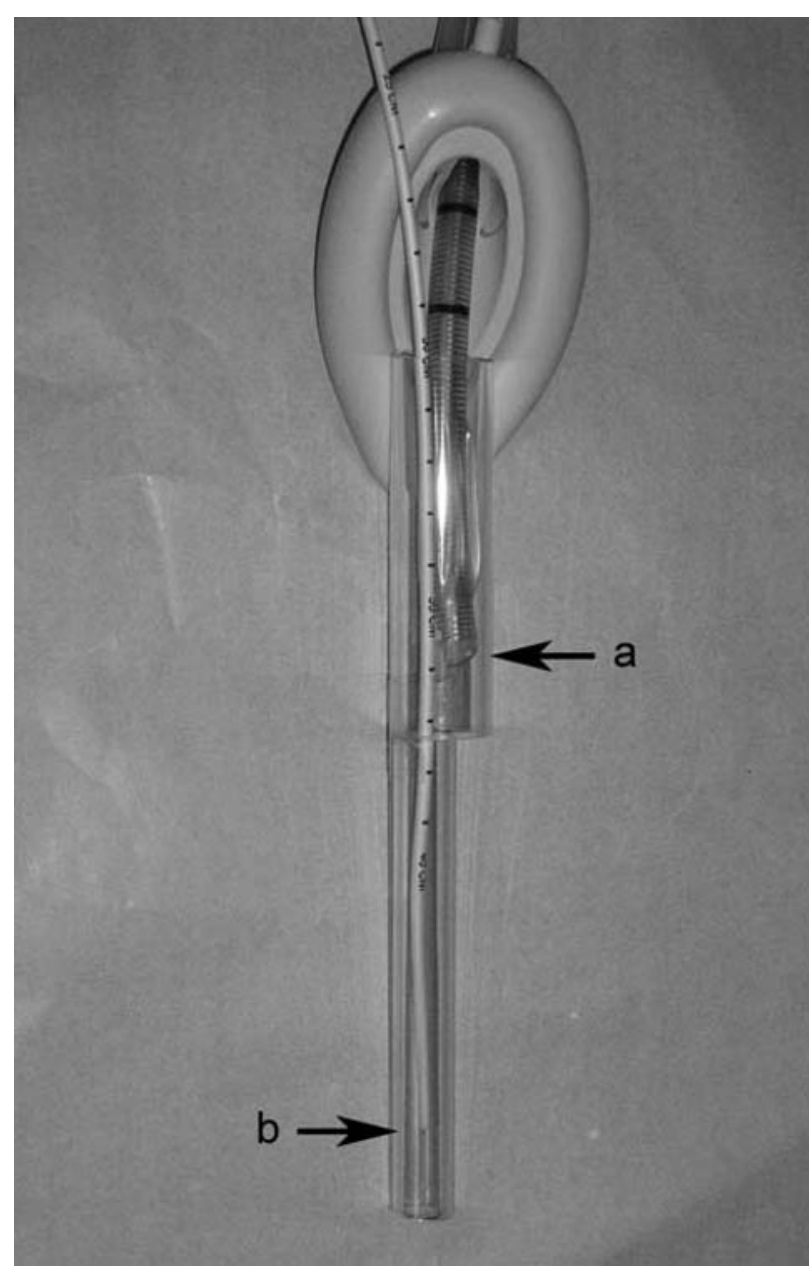

FIGURE A model of the airway management used in this patient with saber-sheath trachea. The acrylic tube represents the trachea (distal part is stenosed). An endotracheal tube is passed through the laryngeal mask airway and the tip of the tube is positioned proximal to the stenotic segment (a). An exchange catheter is inserted orally into the trachea so that its tip is positioned about 2 $\mathrm{cm}$ proximal to the tracheal carina (b). This is left in place to allow jet ventilation in case of accidental intubation.

about $1 \mathrm{~cm}$ proximal to the stenosis. Therefore, only the distal 3 to $4 \mathrm{~cm}$ of the tube were inserted into the trachea (Figure). The cuff of the tracheal tube was not inflated because it was positioned at the glottis. The gap between the tracheal tube and the connector of the laryngeal mask was sealed using adhesive tape. It was possible to ventilate the lungs adequately without leakage of gas around the tracheal tube. With the aid of the fibrescope [(diameter: $3 \mathrm{~mm}$ ) which was passed through the tracheal tube], the exchange catheter was adjusted so that its tip was about $2 \mathrm{~cm}$ proximal to the tracheal carina (Figure). 
The patient was turned to the prone position and the patient's head positioned for surgery. Endoscopy confirmed the appropriate position of the tracheal tube and exchange catheter. The lungs were ventilated mechanically with a tidal volume $7 \mathrm{~mL} \cdot \mathrm{kg}^{-1}$ and 12 breaths $\mathrm{min}^{-1}$. The peak airway pressure was $24 \mathrm{~cm}$ $\mathrm{H}_{2} \mathrm{O}$ so we considered that the exchange catheter was not occupying excessive space in the narrowed airway and that it would be possible to leave the catheter in place. During surgery, no signs of worsening of the stenosis were observed. The end-expiratory carbon dioxide tension and arterial oxygen saturation were within normal limits throughout anesthesia; arterial blood gases were also normal. There was no sign of dislodgment of the tracheal tube. Both the laryngeal mask airway and the exchange catheter were left in place throughout the operation.

After an uneventful intraoperative course, the patient was turned to the supine position, the tracheal tube was removed, and neuromuscular blockade was antagonized with neostigmine. After the patient had regained consciousness without any signs of airway obstruction, the exchange catheter and the laryngeal mask were removed without complications. The postoperative course was uneventful.

\section{Discussion}

Several methods are available to maintain a clear airway in the patient with an uncollapsible tracheal stenosis. One method is to avoid tracheal intubation by using a facemask or the laryngeal mask airway. ${ }^{3,4}$ The use of a facemask was impossible in this patient undergoing neurosurgery in the prone position. Although the laryngeal mask may be used during surgery in the prone position ${ }^{5,6}$ and may be re-inserted while the patient is in this position, ${ }^{6,7}$ its sole use may not be appropriate when access to the patient's airway is restricted and when airway management is more difficult than usual. In this patient, airway management would have been extremely difficult if the trachea had been extubated during the operation, because, in addition to the prone position, the head and neck were fixed in a flexed position for cranial surgery, and access to the airway was restricted by the surgical field. Therefore, we felt it would be safer to intubate the trachea.

In a previous report of airway management of a patient with saber-sheath trachea, in order to dilate the stenosed trachea, the trachea was deliberately fractured using a speculum after a small-bore tracheal tube had been inserted. ${ }^{8}$ However, these procedures may worsen the stenosis. ${ }^{9}$ When tracheal intubation is required in the patient with an uncollapsible tracheal stenosis, the tip of the tube is usually positioned proximal to the stenosis, to avoid possible worsening of the stenosis. In addition, insertion of a tube beyond the stenosis further narrows the diameter of the airway. One major risk associated with placing a tracheal tube proximal to the stenosis is that the tube may be dislodged accidentally from the trachea and a clear airway may be lost. In the patient with a saber-sheath trachea, the intrathoracic part of the trachea is stenosed and thus only the distal 3 to $4 \mathrm{~cm}$ of the tracheal tube can be inserted beyond the glottis.

We used two backup methods to minimize the risk of loosing a clear airway: a laryngeal mask airway and an airway exchange catheter. We considered that if extubation occurred during surgery, the laryngeal mask airway might allow ventilation and/or re-intubation. Accidental extubation in the prone position may usually be minimized by suturing the tracheal tube to the lips or the gum, but this method of fixation cannot prevent extubation secondary to looping of the tracheal tube in the oropharynx. The presence of the laryngeal mask may minimize (although it cannot abolish) this risk. Another problem when positioning a tracheal tube proximal to the stenosis is that the cuff may be positioned at the level of the glottis and damage the vocal cords. We could effectively prevent leakage of gas around the tracheal tube without inflating the cuff by leaving the laryngeal mask over the tracheal tube and sealing the gap between the tracheal tube and the laryngeal mask using adhesive tape. The intubating laryngeal mask might have been an option, but we considered that it was not suitable to leave the device in place for a prolonged period because the metal tube of the device would constantly exert pressure on the surrounding tissues. ${ }^{10}$

The second backup consisted of an airway exchange catheter. By inserting the catheter into the trachea until its tip was positioned near the carina, oxygenation could still have been achieved by applying jet ventilation through the catheter if both the tracheal tube and the laryngeal mask airway had become dislodged. A possible drawback of this method is that the exchange catheter can further narrow the airway and may increase inflation pressure. In this case, we judged that the exchange catheter could be left in place because the peak airway pressure was $24 \mathrm{~cm} \mathrm{H}_{2} \mathrm{O}$.

In conclusion, the laryngeal mask and an airway exchange catheter were used as backups to tracheal intubation in a patient with tracheal stenosis undergoing surgery in the prone position. Had the trachea been extubated accidentally, it could have been reintubated through the laryngeal mask and ventilation would have been possible through the laryngeal mask or the exchange catheter. 


\section{References}

1 Green R, Lechner GL. "Saber-sheath" trachea: a clinical and functional study of marked coronal narrowing of the intrathoracic trachea. Radiology 1975; 115: 265-8.

2 Callan E, Karandy EJ, Hilsinger RL Jr. "Saber-sheath" trachea. Ann Otol Rhinol Laryngol 1988; 97: 512-5.

3 Asai T, Fujise K, Uchida M. Laryngeal mask and tracheal stenosis (Letter). Anaesthesia 1993; 48: 81.

4 Asai $T$, Fujise $K$, Uchida $M$. Use of the laryngeal mask in a child with tracheal stenosis. Anesthesiology 1991; 75: 903-4.

5 Verghese C, Smith TG, Young E. Prospective survey of the use of the laryngeal mask airway in 2359 patients. Anaesthesia 1993; 48: 58-60.

6 Milligan KA. Laryngeal mask in the prone position (Letter). Anaesthesia 1994; 49: 449.

7 McCaughey $W$, Bhanumurthy S. Laryngeal mask placement in the prone position (Letter). Anaesthesia 1993; 48: 1104-5.

8 Bayes J, Slater EM, Hedberg PS, Lawson D. Obstruction of a double-lumen endotracheal tube by a saber-sheath trachea. Anesth Analg 1994; 79: 186-8.

9 Asai T. Tracheal intubation in patients with "sabersheath" trachea (Letter). Anesth Analg 1995; 80: 427-8.

10 Keller C, Brimacombe J, Keller K. Pressures exerted against the cervical vertebrae by the standard and intubating laryngeal mask airways: a randomized, controlled, cross-over study in fresh cadavers. Anesth Analg 1999; 89: 1296-1300. 